\title{
Accuracy of Pedometer Steps and Time for Youth With Intellectual Disabilities During Dynamic Movements
}

\author{
Kenneth H. Pitetti \\ Wichita State University \\ Michael W. Beets \\ University of South Carolina \\ Judy Flaming \\ Newton Unified School District 373
}

\begin{abstract}
Pedometer accuracy for steps and activity time during dynamic movement for youth with intellectual disabilities (ID) were examined. Twenty-four youth with ID (13 girls, $13.1 \pm 3.2 \mathrm{yrs} ; 11$ boys, $14.7 \pm 2.7 \mathrm{yrs}$ ) were videotaped during adapted physical education class while wearing a Walk4Life 2505 pedometer in five locations around the waist. Researchers viewed each videotape and recorded observed steps and activity time. Observed findings were compared with pedometer recorded steps and time. On average, pedometer registered steps were underestimated by approximately $14 \%$ $\pm 16.5 \%$, whereas pedometer registered time was overestimated by approximately $8.7 \% \pm 21.8 \%$. The findings indicate that the accuracy of pedometers may be compromised during dynamic movement for youth with ID.
\end{abstract}

For school-age youth (K-12) with and without disabilities, daily physical activity (PA) is essential for the promotion of health, growth, and development as well as reducing risk factors for adult onset of cardiovascular and metabolic diseases (Rimmer \& Rowland, 2008; Strong et al., 2005). Common methods used to assess patterns of PA in children and adolescents include self-report, heart rate monitoring, direct observation, pedometry, and acclerometry. The feasibility, reliability, and validity of each of these methodologies, as well as their strengths and limitations, have been addressed in prior studies (Beets, Combs, Pitetti, Morgan, Bryan, \& Foley, 2007; Bjornson \& Belza, 2004; Bjornson, 2005; Eston, Rowlands, \& Ingledew, 1998; Kohl, Fulton, \& Caspersen, 2000; Rowlands, 2001; Rowlands, Eston, \& Ingledew, 1997; Tudor-Locke, Williams, Reis, \& Pluto, 2002.). Of these, pedometry has become a popular method of measuring PA in

Kenneth H. Pitetti is with the Department of Physical Therapy in the College of Health Professions at Wichita State University in Wichita, KS. Michael W. Beets is with the Department of Exercise Science at the University of South Carolina in Columbia. Judy Flaming is with the Newton Unified School District \# 373 in Newton, KA. 
children and adolescents because of its moderate to high correlations with other objective measures of PA such as heart rate monitors and accelerometry (Bjornson \& Belza, 2004, Bjornson, 2005; Eston et al., 1998). In addition, it is inexpensive, involves minimal staff training and time commitment, and, thus, allows for large population studies and practitioner use.

The construct validity of pedometers in determining PA of youth has been determined by comparing pedometers to various objective measures of PA. These include direct behavior observations (Nishikido, Kashiwazaki, \& Suzuki, 1982; Kilanowski, Conslavi, \& Epstein, 1999; Scruggs, Beveridge, Eisenman, Watson, Shultz, \& Ransdell, 2003; Scruggs, 2007), heart rate monitoring (Eston et al., 1998, Louie, Eston, Rowlands, Tong, Ingledew, \& Fu, 1999), accelerometry (Eston et al., 1998; Jago, Watson, Baranowski et al., 2006; Kilanowski et al., 1999; Louie et al., 1999) and oxygen uptake scaled for body mass (Eston et al., 1998; Louie et al., 1999). Correlations ranged from moderate to high (0.50-0.98); however, correlation studies are not designed to answer whether step count, recorded by a pedometer, are accurate (i.e., actual steps taken vs. steps recorded). Rather, the correlation studies determined whether a high step count corresponds to high measures (e.g., beats per minute, METS) from other objective activity monitoring devices. The concern of recorded steps vs. actual steps is related to the highly transitory (i.e., sporadic and spontaneous) and dynamic (i.e., jumping and skipping) characteristic of school age children (Bailey, Olson, Pepper, Porszasz, Barstow, \& Cooper, 1995; McArdle, 2001; Pellegrini, 1990; Riddoch et al., 2004; Saris, 1986). That is, a good portion of PA in school age children may not necessarily involve walking movements.

The accuracy studies performed to date have primarily investigated actual vs registered steps during varying walking speeds (Beets, Combs et al., 2007; Beets, Foley, Tindall, \& Lieberman, 2007; Beets, Patton, \& Edwards, 2005; Crouter, Schneider, Karabulut, \& Bassett, 2003; Crouter, Schneider, \& Bassett, 2005; Cytarto, Myers, Tudor-Locke, 2004; Le Masurier, Lee, \& Tudor-Locke, 2004; Le Masurier, Lee, \& Tudor-Locke, 2004; Schneider, Crouter, Lukajic, \& Bassett, 2003; Schneider, Crouter, \& Bassett, 2004). However, as addressed above, the day-to-day locomotion of youth includes transitory and dynamic movements, movements not included in these accuracy studies (Beets, Combs et al., 2007; Beets, Foley et al., 2007; Crouter et al., 2003; Crouter et al., 2005; Cytarto et al., 2004; Le Masurier \& Tudor-Locke, 2003; Le Masurier et al., 2004; Schneider et al., 2003; Schneider et al., 2004). Therefore, the accuracy of pedometers for children involved in free play, which includes walking, transitory, and dynamic movements, has not been established for children and adolescents with and without disabilities.

The focus of this study in determining the accuracy of pedometers concerns children and adolescents with ID. The critical need for such research specific to youth with disabilities was ably addressed in two recent articles (Frey, Stanish, \& Temple, 2008; Rimmer \& Rowland, 2008). In the article by Rimmer and Rowland (2008) it was stated, "One of the most important challenges for paediatric rehabilitation and healthcare professionals is finding ways to increase physical activity and fitness among youth with disabilities in community-based settings" (p. 141). To determine levels of physical activity in youth with disabilities it is necessary to establish the most valid and accurate method to measure their activity. The need 
to establish accuracy of pedometers in children with ID for movement other than walking was specifically addressed in the review article by Frey et al. (2008): "It is important that the limitations of the measurement tool be considered and addressed, and findings interpreted accordingly. For example, pedometers are only an assessment of walking behavior, which is a component of daily activity, not a global measurement of physical activity." (p. ???).

The present study represents an attempt to determine if pedometry is accurate, and therefore, could be used to determine physical activity levels in children and adolescents with ID within a common community settings- the school. If pedometers fail to accurately capture physical activity levels of children and adolescents with ID while engaged in routine or typical activity patterns, then the use of pedometers to assess physical activity levels in this population would need to be supplemented by additional measures (e.g., heart rate, accelerometers, observation).

Therefore, the purpose of this study is to extend the findings of Beets, Combs et al. (2007) and examine the accuracy of pedometry in children and adolescents with ID engaged in dynamic movements during adapted physical education. For this study, accuracy was defined as number of actual steps (i.e., measured by video) compared with recorded step counts by pedometry; dynamic movement was defined as any activity preformed during school sponsored adapted physical education class.

\section{Methods}

\section{Participants}

Twenty-four elementary, middle school, and high school youth with developmental disabilities (ID) participated in this study (see Tables 1 and 2 for descriptive characteristics). The schools were located in a midwestern city. As of the Consensus of 2000, the city had a population of 17,190, a median household income of $\$ 38,000$, with $5.1 \%$ of the families and $7.9 \%$ of the population below the poverty line. The racial make-up of the participants was 18 White non-Hispanic and 6 Hispanics. The sampling design was purposive (Henry, 1990; Sherrill \& O'Conner, 1999 ) in that the participants were classified with mild mental retardation and were attending schools that employed staff trained to teach students with these disabilities.

Table 1 Participant Demographics by Gender

\begin{tabular}{lcccccc}
\hline & \multicolumn{2}{c}{$\begin{array}{c}\text { Girls } \\
(\boldsymbol{n}=\mathbf{1 3})\end{array}$} & & & \multicolumn{2}{c}{$\begin{array}{c}\text { Boys } \\
(\boldsymbol{n}=\mathbf{1 1})\end{array}$} \\
\cline { 2 - 3 } \cline { 6 - 7 } Variable & $M$ & $S D$ & & $M$ & $S D$ \\
\hline Age (yrs) & 13.1 & 3.2 & & 14.7 & 2.7 \\
Weight $(\mathrm{kg})$ & 49.4 & 19.8 & & 70.2 & 26.5 \\
Height (m) & 1.5 & & 0.2 & & 1.6 & 0.2 \\
Body Mass Index $\left(\mathrm{kg} \bullet \mathrm{m}^{-2}\right)$ & 21.3. & & 6.9 & & 25.6 & 7.0 \\
\hline
\end{tabular}


Table 2 Individual Participant Demographics

\begin{tabular}{|c|c|c|c|c|c|}
\hline Participant & Gender & $\begin{array}{l}\text { Age } \\
\text { (yrs) }\end{array}$ & $\begin{array}{c}\text { Weight } \\
\text { (kg) }\end{array}$ & $\begin{array}{c}\text { Height } \\
\text { (m) }\end{array}$ & $\begin{array}{c}\text { BMI } \\
\text { kg॰m }^{-2}\end{array}$ \\
\hline 1 & $\mathrm{~F}$ & 11.1 & 36.4 & 1.37 & 19.4 \\
\hline 2 & $\mathrm{~F}$ & 11.2 & 46.4 & 1.47 & 21.5 \\
\hline 3 & M & 9.4 & 29.0 & 1.31 & 16.7 \\
\hline 4 & $\mathrm{~F}$ & 8.7 & 23.6 & 1.19 & 16.6 \\
\hline 5 & $\mathrm{~F}$ & 11.3 & 72.7 & 1.43 & 35.6 \\
\hline 6 & $\mathrm{~F}$ & 11.8 & 27.7 & 1.32 & 14.2 \\
\hline 7 & $\mathrm{~F}$ & 10.5 & 38.6 & 1.38 & 20.3 \\
\hline 8 & M & 15.2 & 55.9 & 1.60 & 21.8 \\
\hline 9 & $\mathrm{~F}$ & 12.3 & 92.3 & 1.61 & 36.3 \\
\hline 10 & M & 13.4 & 30.0 & 1.32 & 17.2 \\
\hline 11 & M & 12.8 & 62.3 & 1.75 & 20.4 \\
\hline 12 & M & 15.4 & 99.5 & 1.78 & 31.4 \\
\hline 13 & M & 19.0 & 73.2 & 1.71 & 25.3 \\
\hline 14 & M & 15.3 & 96.4 & 1.73 & 32.2 \\
\hline 15 & $\mathrm{~F}$ & 19.4 & 67.7 & 1.75 & 22.0 \\
\hline 16 & M & 15.2 & 108.6 & 1.64 & 40.6 \\
\hline 17 & M & 14.9 & 74.5 & 1.73 & 24.9 \\
\hline 18 & $\mathrm{~F}$ & 19.1 & 67.7 & 1.75 & 22.1 \\
\hline 19 & $\mathrm{~F}$ & 14.8 & 39.5 & 1.65 & 14.5 \\
\hline 20 & M & 15.8 & 57.3 & 1.57 & 23.3 \\
\hline 21 & $\mathrm{~F}$ & 14.9 & 45.5 & 1.66 & 16.5 \\
\hline 22 & M & 13.5 & 85.5 & 1.74 & 28.2 \\
\hline 23 & $\mathrm{~F}$ & 11.9 & 45.9 & 1.66 & 16.6 \\
\hline 24 & $\mathrm{~F}$ & 14.3 & 38.6 & 1.42 & 19.3 \\
\hline Mean & & 13.7 & 59.0 & 1.56 & 23.2 \\
\hline$S D$ & & 2.9 & 25.0 & .17 & 7.2 \\
\hline
\end{tabular}

All participants had been classified as having mild mental retardation as determined by qualified school district personnel according to the model for diagnosis by the American Association on Mental Retardation (2002). Primary exceptionality was determined by the classification provided on each participants' Individualized Education Plan (IEP). Inclusion criteria included the ability to maintain a steady state gait pattern without an assistive device (i.e., need for crutches, walker, foot orthotics, knee brace, and/or wheelchair) during the school day (i.e., no physical disabilities that restricted ambulation). Informed parental consent and voluntary assent, along with district and school administration approval were obtained before participation in the study. All measures were administered during regularly scheduled physical education class.

For descriptive statistics, standing height $(\mathrm{cm})$ and weight $(\mathrm{lbs})$ were obtained without shoes using a portable stadiometer (Seca 214 Portable Height Rod, Ham- 
burg, Germany) and physician's scale (Detecto Balance Beam Scale, Daugherty Webb City, MO). The units (e.g., lbs to kg) were converted and body mass index $\left(\mathrm{BMI}, \mathrm{kg} \bullet^{-2}\right)$ calculated. Participant's age (yr, in decimal) was calculated by subtracting their date of birth from the date of assessment.

\section{Materials}

The Walk4Life Duo 2505 (WL, Plainfield IL), which assesses both steps and activity time (hours, minutes, seconds) was used throughout the study. The selection of this pedometer was based on previous work which indicated this specific model/brand exhibited a high degree of accuracy, specifically the time parameter, in children with and without disabilities (Beets, Patton, \& Edwards, 2005; Beets, Combs et al., 2007). A total of ten units were used, with five units serving as the primary pedometers for the entirety of the study. The additional five pedometers served as reserve models in case of primary unit failure. No primary unit failure occurred during the study. All units were subjected to a modified version of the "shake-test" (Vincent \& Sidman, 2003) at pre, mid, and post testing. Briefly, all units were reset to zero and placed in single compartments inside a plastic container $(30 \times 20 \times 4 \mathrm{~cm})$. The container was then shaken 100 times while the research staff member counted the number of shakes with a hand tally counter. This procedure was performed three times at each shake-test. No unit exhibited more than $\pm 5 \%$ error across the shake tests.

\section{Data Collection}

Dynamic Movement. Each participant was fitted with an adjustable belt with pedometers placed at five positions around the waist. The pedometer positions were front right hip (manufacturer's recommended placement), back right hip, front left hip, back left hip, and middle back at the spine. These positions were selected in accordance with prior research (Beets, Combs, et al., 2007). Before each trial the pedometers were positioned around the waist, reset to zero, and closed. To ensure that movement was minimized before beginning each trial, participants were instructed or held still by the adapted physical education teacher or research group members. Once all pedometers were in their proper position, reset to zero and closed, participants were allowed to begin engaging in dynamic movements or free play during their adapted physical education class (see description below). Each participant was videotaped using a single video camera (Sony Mini Camcorder, Model \# DCR-TRV, 950) for 5-6 min while participating in the adapted physical education class activity. The staff member recording participant movement held the video approximately at shoulder height and recorded while following the participant throughout the activity within a $10 \mathrm{~m}$ distance.

Physical education class took place in a gymnasium and consisted of one of six types of activities: (a) indoor baseball (using soft plastic ball), (b) volleyball, (c) basketball, (d) field hockey, (e) ball catching and throwing games, and/or (f) "tag" games. Videotaping started before the first step each participant took after placement of the five WL pedometers attached to the adjustable belt and concluded after 5-6 min of dynamic movement. At the end of the 5-6 min period, each participant was either instructed to stand still or held while the research 
group members recorded the step and time readings from each pedometer at each of the five locations on the belt.

Step/Time Criterion Measure. The videos were transferred to DVD and two of the research group members watched them independently on computers using Windows Media Player 10 (Microsoft Corporation, Inc.). Each participant's DVD was viewed at one-half speed (i.e., slow motion) to ensure an accurate count of the number of steps taken during each participant's trial. A step was defined as the elevation of the foot from the ground. The definition of "step" was based on the location of the pedometer at the center of the body at the waist, the location where most (if not all) of the full body movement would be recorded, and, secondly, the majority of the activities students perform during adapted physical education required vertical movement at the hip, such as walking, running, jumping, bouncing, and skipping (Bassett et al., 1996; Crouter et al., 2003; Ramirez-Marrero, Smith, Kirby, Leenders, \& Sherman, 2002). Each of these movements is associated with movement at the hip, most likely due to an elevation of the foot (or feet) off the ground. Hence, the research video reviewers were trained to identify and hand tally (using handheld tally counters) elevations of the feet from the ground. Time for each participant's trial was determined using the digital elapsed time readout (hours: minutes: seconds) appearing on the media information window. Durations of pausing longer than one second were tallied and subtracted from the total time each participant was filmed. This adjusted time (minus pauses) was used as the criterion to compare activity time. To remove potential bias, DVDs of the trials were viewed by two research staff members who were not involved in the primary collection of dynamic movement pedometer steps and time.

Before reviewing and recording the actual number of steps and elapsed activity time from the videos, the two research staff members who viewed and recorded steps and time watched three training videos. They recorded actual steps and activity time for each video. These values were compared with the number of steps and elapsed activity time assessed by the primary authors. The viewers were required to review the video until their values (i.e., steps and activity time) were within $\pm 5 \%$ of the criterion. Systematic checks were preformed by the primary authors throughout the study to ensure accuracy of results.

\section{Data Analysis}

Inter-Observer Agreement. Two way mixed model single measure correlation coefficients (ICC) and 95\% confidence intervals (95CI) were calculated to determine the agreement between two observers for actual steps and activity time (i.e., criterion measure, see above) estimates from the videos. Single measure ICCs (95CI) for actual pedometer steps and activity time were ICCsteps $=.95$ (95\% CI .88 to .98$)$ and ICCtime .96 (95\%CI .91 to .98), respectively. Given the high agreement between the two raters, the average of actual steps and activity time were calculated and used as the criterion measure to determine accuracy for all subsequent analyses.

Step and Activity Time Percent Error Comparisons. For each trial, the absolute difference among pedometer registered steps and activity time to criterion measured steps and activity time (i.e., via video) was computed (pedometer registered 
steps minus criterion measured steps) for each of the five pedometer locations, separately (Le Masurier \& Tudor-Locke, 2003). The difference scores were transformed into two percentages for each location for steps and time, separately. In addition, the average differences in scores across the five locations were calculated for steps and time, separately. Thus, for steps and time, six difference scores were calculated (five for each location and one average across the five locations). The first percentage was the percent error (referred to as the average percent error score) and was calculated by taking the pedometer registered steps minus criterion steps divided by the criterion steps $\times 100$ to reflect the percent error (positive or negative) from observed. The second percentage was the absolute percent error score and was the same calculation as the average percent error score, disregarding the direction of the error (i.e., positive or negative). These transformations were performed to examine the difference in the accuracy between steps and activity time in the subsequent analyses. Means (standard deviations) of the percent error scores were calculated for all variables. Preliminary analyses indicated no significant differences existed between boys and girls' percent error scores for steps and activity time across the five pedometer locations.

Comparison of Percent Error Scores by the Five Pedometer Locations. Overall, two one-way within-subjects ANOVAs, assessing the effects of pedometer placement (i.e., five locations) on the percent error scores (dependent variable) for steps and activity time, were computed. For all ANOVAs, Mauchley's test for sphericity was examined for violation, with significant violations corrected using the Greenhouse-Geisser adjusted degrees of freedom and corresponding $p$ values (Greenhouse \& Geisser, 1959). The magnitude of the effect was determined by the partial eta squared $\left(\eta^{2}\right)$. Paired sample $t$ tests were calculated to examine differences in percent error scores for steps and activity time for each pedometer placement (e.g., front right steps percent error vs. front right activity time percent error). An alpha level of $p \leq .05$ was used to indicate significant differences.

\section{Results}

The mean (standard deviation) absolute percent error scores and average percent error scores are presented in Table 3 and Figures 1 and 2. The average time the participants were viewed being active during the observation period (5-6 min) was $71.6 \pm 11.8 \%$ or $4.3 \pm 0.7 \mathrm{~min}$. For steps, the results for the one-way withinsubject ANOVA in examining the difference in the absolute percent error scores among location was significant $\left(F_{\text {df } 2.8,65.2}=6.318, p=.001, \eta^{2}=.22\right)$. Follow-up pairwise analyses indicating the FR was significantly higher than the BR, the BR was significantly lower than the BL and FL, while the FL was significantly higher than the MB. For time, the results of the one-way within-subject ANOVA indicated a nonsignificant difference among locations $\left(F_{\mathrm{df} 2.8,64.3}=2.01, p=.116, \eta^{2}\right.$ $=.08$ ). Paired sample $t$ tests, comparing absolute percent error scores for steps and time for each location indicated only the steps and time for the BR were significantly different from one another $\left(t_{\mathrm{df} 23}=-2.53, p=.02\right)$. The average percent error scores are graphically presented in Figure 2 (corresponds to average percent error scores presented in Table 2). Overall, pedometer registered steps were under 


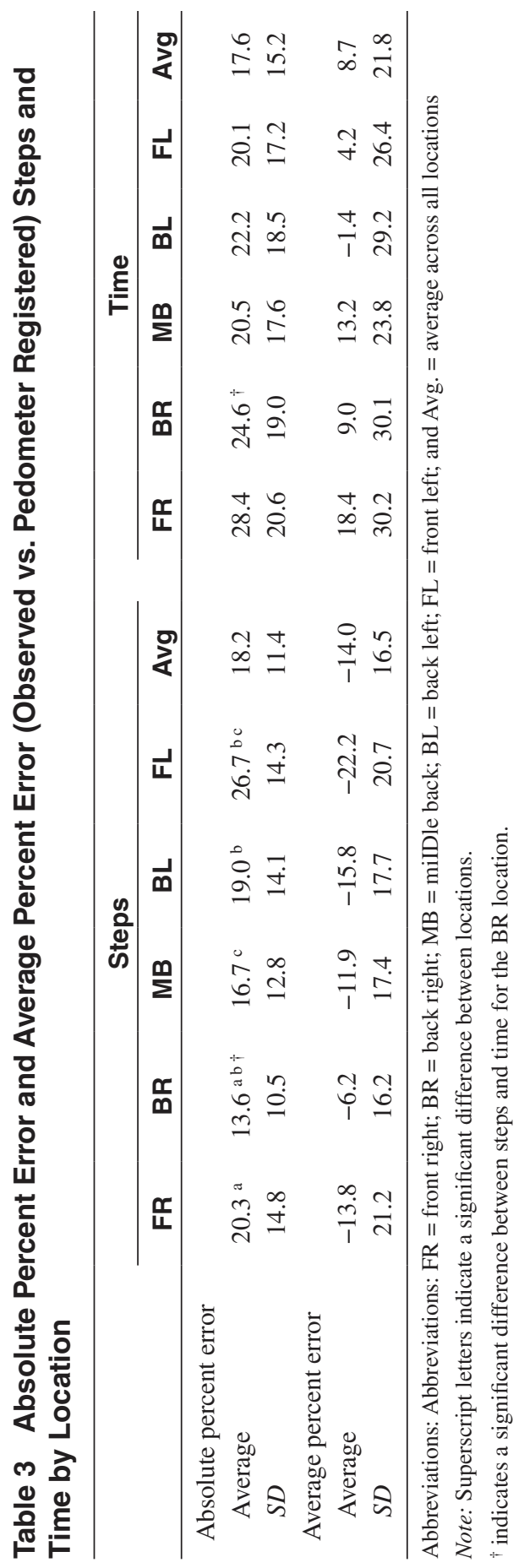




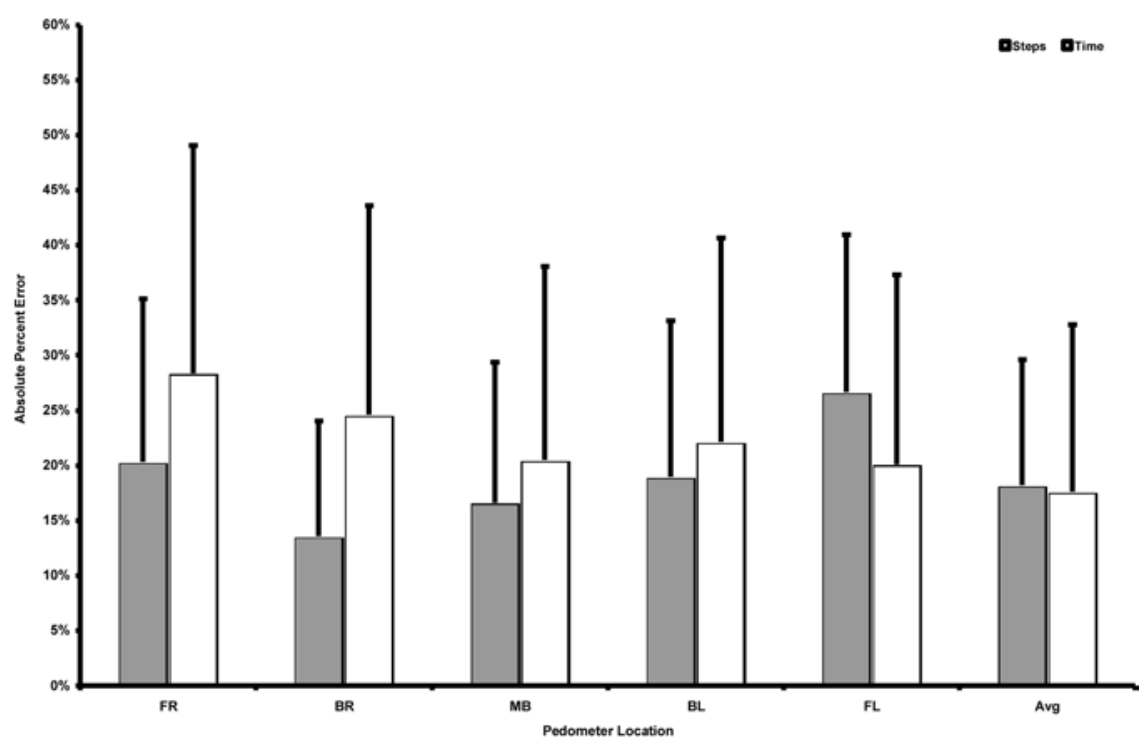

Figure 1 - Absolute percent error between observed vs. registered pedometer steps and time $(N=24)$. Error bars represent 1 standard deviation. Abbreviations: FR = front right; $\mathrm{BR}=$ back right; $\mathrm{MB}=$ miIDle back; $\mathrm{BL}=$ back left $\mathrm{FL}=$ front left; and Avg. = average across all locations

recorded by approximately $14 \%( \pm 16.5)$, while pedometer registered time was over recorded by approximately $8.7 \%( \pm 21.8 \%)$.

\section{Discussion}

In recent decades the interest to measure physical activity in children and adolescents has increased due to the link between physical activity and lifestyle-related morbidities in the pediatric population (Hayman et al., 2004) . To further understand physical activity behaviors of youth, accurate and objective physical activity-surveillance systems (accelerometers, pedometers, heart rate monitors, observation) have been developed (Bjornson \& Belza, 2004, Bjornson, 2005; Eston, Rowlands, \& Ingledew, 1998; Kohl et al., 2000; Rowlands, 2001; Rowlands et al., 1997; Tudor-Locke et al., 2002). The results of this study suggest that the accuracy of pedometry may be compromised during dynamic movement of youth with ID.

Although it has been reported that youth with physical (e.g., cerebral palsy) and sensory (e.g., limited visual capacity) disabilities engage in less recreational activities than their peers without disabilities (Longmuir \& Bar-Or, 2000), little is known about the physical activity patterns of youth with ID (Fernhall \& Unnithan, 2002; Frey et al., 2008; Rimmer and Rowland, 2008). The use of pedometry could provide insight into their physical activity patterns. In a preliminary study, Beets, Combs et al., (2007) reported acceptable accuracy for pedometry in steps and time for youth with ID when walking in a controlled setting. However, given the vari- 

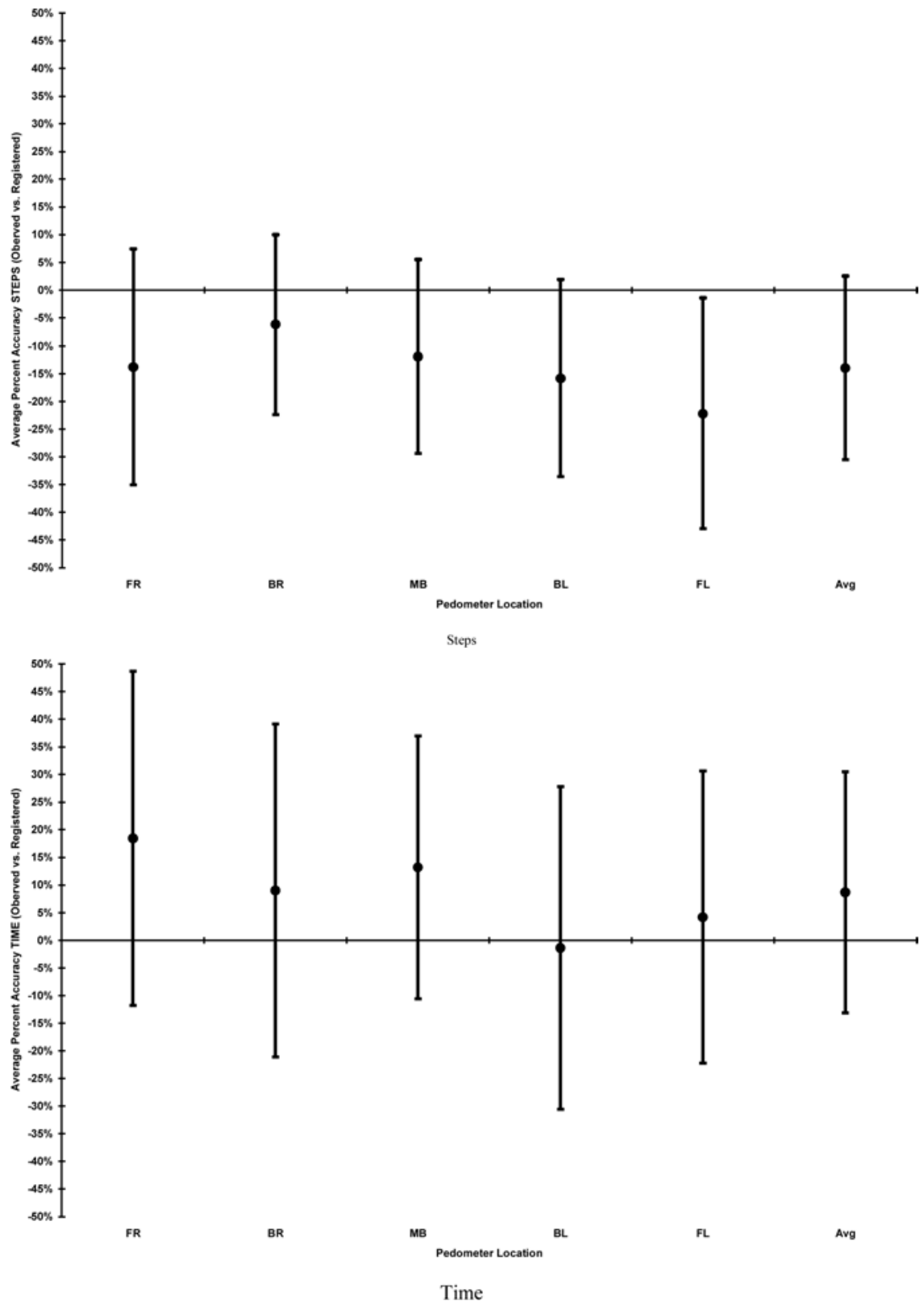

Figure 2 - Average percent accuracy between observed vs. pedometer registered steps and time $(N=24)$. Error bars represent $\pm 1 S D$. Abbreviations: $F R=$ front right; $\mathrm{BR}=$ back right; $\mathrm{MB}=$ miIDle back; $\mathrm{BL}=$ back left; $\mathrm{FL}=$ front left; and Avg. = average across all locations. 
able, dynamic and transitory movement of school age children (Bailey et al., 1995; McArdle, 2001; Pellegrini, 1990; Riddoch et al., 2004; Saris, 1986), the accuracy of pedometry for youth with ID during these movements was not known. Therefore, it was the purpose of this study to determine accuracy of pedometry in youth with ID engaged in dynamic movements occurring in adapted physical education class.

\section{Present Study vs. Beets, Combs et al. (2007)}

With the exception of the types of movement performed by participants, the methodology used by Beets, Combs et al. (2007) was similar to the current study in terms of model of pedometer, placement of pedometers, and use of video tapes to determine pedometer step and activity time accuracy; however, the results of the two studies are different. Beets, Combs et al. (2007) demonstrated relative accuracy as defined by Hatano, (1993; minimum threshold set at 3\%), whereas the current study did not. When excluding the outlier, Beets, Combs et al. (2007) reported absolute percent error scores for pedometer steps and activity time by location ranging from $5.6 \%$ to $10.8 \%$ and $3.6-4.9 \%$, respectively. In the current study, absolute percent error scores for pedometer steps and time ranged from $13.6 \%$ to $26.7 \%$ and $20.5-28.4 \%$ (see Table 2), respectively. In addition, Beets and colleagues (Beets, Combs et al., 2007) reported activity time was more accurate than steps whereas in the current study the average absolute percent error for time (17.6\%) and steps (18.2\%) were equally substantial (see Table 2 and Figure $1)$.

Given that the methodology of the current study and that by Beets, Combs et al. (2007) differed only in the type of activity performed by the participants, the conflicting results of the two studies may well reside in the activity mode of the participants. In the study by Beets, Combs et al. (2007), participants' locomotion was controlled in that it involved self-paced walking trials, walking a 10-m distance eight times in a straight line guided by a pacer. Similar methodologies were used (i.e., walking) in previous studies have evaluated the precision of various models of pedometers in adults with disabilities (Stanish, 2004) and children without disabilities (Beets et al., 2005; Ramirez-Marrero et al., 2002). In the current study, however, the participants were allowed to move freely in response to the activity they were performing during physical education classes. The findings in the current study when compared with those by Beets and colleagues (Beets et al., 2005; Beets, Combs et al., 2007) and Ramirez-Marrero et al. (2002) suggests a cautionary approach to using pedometers when measuring the physical activity levels of youth. Given the variability in movement in children (Bailey et al., 1995; McArdle, 2001; Pellegrini, 1990; Riddoch et al., 2004; Saris, 1986), the possibility exists that when measuring physical activity of school age youth, a portion of that activity may not involve walking movements.

A comparison in the current study between pedometer steps and activity time that was not addressed by Beets, Combs et al. (2007) concerned the direction of error for step count and activity time. Pedometry steps consistently under predicted actual steps with an average percent error of $-14 \%$ (Table 2, Figure 2) while pedometry time over predicted actual time by an average percent error of $8.7 \%$ (Table 2, Figure 2). The types of movement observed by the authors that could 
have affected pedometry accuracy were falling, rocking/swaying and bending over to pick up objects. Crouter and colleagues (Crouter et al., 2005) reported that pedometer tilt (angle of deviation away from or toward the body) due to overweight and obesity contributes to inaccuracy of registered steps counts. Although overweight and obesity was not the focus of the current study, pedometer tilt could have been involved in the percent error. That is, the recording of time is not dependent on a registered step count. Although falling, rocking/swaying, or bending over may have caused the lever arm to be in motion to register time, the downward force generated by these movements may not have been great enough to cause the electronic circuit to record the step. Therefore, in some movements, the staff members viewing the tapes could have registered steps (defined as elevation of the foot from the ground), but the step was not registered by the pedometer because of it's tilt (i.e., bending over at the waist or recovering from a fall). Whereas in some movements (i.e., rocking or swaying) the lever arm could have been set in motion, but the observers did not register movement because the participants' feet never left the ground.

In the study by Beets, Combs et al. (2007), five locations were used for placement of the pedometers for two reasons: a) determine the appropriate placement of the pedometers for accurate register of steps and time for youth with ID; and b) whether placement out of direct view of the child (i.e., back left/right hip and the middle back) could be used to minimize the children interfering with the pedometer while wearing. Results of the study by Beets, Combs et al. (2007) indicated that left hip location (i.e., the commonly recommended placement position) demonstrated the highest absolute percent error scores for both activity time and steps, with the lowest error scores registered by the back left/right hip and middle back. Similar results were seen in this study in that the three lowest absolute percent errors for steps were registered by the back left/right hip and middle back. Although the absolute percent errors for steps at these locations for the current study would be considered significant (mean of 13.6-19.0), the results of both studies suggest that when considering accuracy for step count in youth with ID, the back locations would allow for the highest accuracy as well as reduce behavioral interference (i.e., "out of sight, out of mind").

\section{Present Study vs. Scruggs (2007)}

This cautionary approach in using the pedometer to measure activity level in children has also been suggested in a recent study by Scruggs (2007). In that study pedometry physical activity time output of children (8-12 yrs) without disabilities was compared with observation (i.e., System for Observing Fitness Instruction Time, SOFIT) during a school-based structured physical activity program. As in the current study, Scruggs (2007) reported that physical activity time outputs, measured by the same type of pedometer used in this study (Walk4Life Duo 2505), overestimated actual time and are "clinically acceptable when physical activity is continuous, but not when physical activity is intermittent, either at low or high volume" (p. 1845). In addition, it was also suggested (Scruggs, 2007) that when physical activity is not continuous, pedometer activity time should be cautiously interpreted. Although the participants in this study (Scruggs, 2007) were not classified as having a disability, the type of activity performed (i.e., school- 
based structured physical activity program) was similar to that performed in this study (i.e., adapted physical education class).

\section{Limitations and Recommendations}

A potential limitation of the current study is that although pedometer step function was calibrated before data collection by the shake test, time function was not; however, the study by Beets and colleagues (2005) reported that the Walk4lifeDuo2505 pedometer's time did not vary more than $5.3 \mathrm{~s}$ from actual time across all speeds and between units. In addition, our data collection involved five pedometers and the results indicate that for time, there were no significant differences among the five locations for absolute percent error. Therefore, it is felt that pedometer time reported in this study is accurate and the finding that pedometer time overestimated actual time is valid.

A second potential limitation of the current study concerns the number of total minutes the children were observed. In the current study, the average time the participants were viewed being active during the observation period (5-6min) was $4.3 \pm 0.7 \mathrm{~min}$. The possibility exists that the standard errors of $14 \%( \pm 16.5)$ for registered steps and $8.7 \%( \pm 21.8 \%)$ for recorded time could be inflated in that more observation time might have resulted in lower standard errors. Therefore, the optimal time necessary to determine the accuracy of pedometer step counts and time of youth with and without disabilities during free-play activity is an issue for future research. The average number of steps/min in this study, however, was 86 steps/min ( \pm 16.1$)$, which is slightly higher than activity levels reported by Scruggs (2007) for children and adolescents without disabilities during a schoolbased physical activity program (71.7 \pm 26.8 steps/min; Scruggs, 2007). Therefore, while the total time each participant was observed averaged 5-6 min, the amount of activity they performed within this observation period was comparable to what is observed for children without disabilities during a similar school-based physical activity program.

\section{Importance of the Study}

When considering youth with ID, the findings of this study are important for the following reason. There is a need to increase physical activity of youth with disabilities in community based settings (Rimmer \& Rowland, 2008). To determine activity level of youth with disabilities in the community settings, valid and reliable methods used to measure physical activity in youth without disabilities must be shown valid and reliable for youth with ID (Frey et al., 2008). For instance, Scruggs et al. (2003) have suggested that intensity of activity (e.g., MVPA) can be measured or estimated from number of steps per minute measured by pedometry. Using the SOFIT as the criterion instrument and the Yamax SW-701 pedometer as the predictor instrument, Scruggs et al. (2003) established steps per minute cut points $(60.0,60.63$, and 61.14$)$ as the best indicators for time spend in MVPA within a 30-min physical education class for first- and second-grade nondisabled children. Whether differences in types of movement exist between children with and without ID during physical education is not known; however, the results of the current study does suggest that a cautionary approach should be taken when 
attempting to measure MVPA of children with ID using pedometer measured cut points for steps established for children without disabilities.

\section{Conclusion}

The purpose of this study was to extend the findings of Beets, Combs et al. (2007) and examine the accuracy of pedometry in children and adolescents with developmental disabilities engaged in dynamic movements during adapted physical education. The results of this study suggest that the accuracy of pedometers may be compromised during dynamic movement of youth with ID in that pedometry may underestimate steps and overestimate time. Therefore, a cautionary approach should be taken when using pedometry to objectively measure their physical activity in movement other than walking.

\section{References}

American Association on Mental Retardation. (2002). Mental retardation: Definition, classification, and systems support (10th ed.). Washington, DC: American Association on Mental Retardation.

Bailey, R.C., Olson, J., Pepper, S.L., Porszasz, J., Barstow, T.J., \& Cooper, D.M. (1995). The level and tempo of children's physical activities: an observational study. Medicine and Science in Sports and Exercise, 27, 1033-1041.

Bassett, D.R., Ainsworth, B.E., Legget, S.R., Mathien, S.R., Main, C.A., Hunter, J.A., et al. (1996). Accuracy of five electronic pedometers for measuring distance walked. Medicine and Science in Sports and Exercise, 28, 1071-1077.

Beets, M.W., Patton, M.M., \& Edwards, S. (2005). The accuracy of pedometer steps and time during walking in children. Medicine and Science in Sports and Exercise, 37, 513-520.

Beets, M.W., Combs, C., Pitetti, K.H., Morgan, M., Bryan, R.R., \& Foley, J.T. (2007). Accuracy of pedometer steps and time for youths with disabilities. Adapted Physical Activity Quarterly, 24, 228-244.

Beets, M.W., Foley, J.T., Tindall, W.S., \& Lieberman, L.J. (2007). Accuracy of voice-announcement pedometers for youth with visual impairment. Adapted Physical Activity Quarterly, 24, 218-227.

Bjornson, K.F., \& Belza, B. (2004). Ambulatory activity monitoring in youth: State of the science. Pediatric Physical Therapy, 16, 82-89.

Bjornson, K.F. (2005). Physical activity monitoring in children and youths. Pediatric Physical Therapy, 17, 37-45.

Crouter, S.E., Schneider, P.L., Karabulut, M., \& Bassett, D.R. (2003). Validity of 10 electronic pedometers for measuring steps, distance, and energy cost. Medicine and Science in Sports and Exercise, 35, 1455-1460.

Crouter, S.E., Schneider, P.L., \& Bassett, D.R. (2005). Spring-levered versus piezo-electric pedometer accuracy in overweight and obese adults. Medicine and Science in Sports and Exercise, 37, 1673-1679.

Cytarto, E.V., Myers, A.M., \& Tudor-Locke, C. (2004). Pedometer accuracy in nursing home and community-dwelling older adults. Medicine and Science in Sports and Exercise, 36, 205-209.

Eston, R.G., Rowlands, A.V., \& Ingledew, D.K. (1998). Validity of heart rates, pedometry, and acclerometry for predicting the energy cost of children's activities. Journal of Applied Physiology, 84, 362-371. 
Fernhall, B., \& Unnithan, V.B. (2002). Physical activity, metabolic issues, and assessment. Physical Medicine and Rehabilitation Clinics of North America, 13, 925-947.

Frey, G.C., Stanish, H.I., \& Temple, V.A. (2008). Physical activity of youth with intellectual disability: Review and research agenda. Adapted Physical Activity Quarterly, 25, 95-117.

Greenhouse, S.W., \& Geisser, S. (1959). On the methods in the analysis of profile data. Pschometrika, 24, 95-112.

Hatano, Y. (1993). Use of the pedometer for promoting daily walking exercise. Journal of the International Council for Health, Physical Education, Recreation. Sport \& Dance, 29, 4-8.

Hayman, L.L., Williams, C.L., Daniels, S.R., Steinberger, J., Paridon, S., Dennison, B., et al. (2004). Cardiovascular health promotion in the schools. Circulation, 110, 22662275.

Henry, G.T. (1990). Practical sampling. Thousand Oaks, CA: Sage.

Jago, R., Watson, K.B., Baranowski, T., et al. (2006). Pedometer reliability, validity, and daily activity targets among 10-to 15-year-olds boys. Journal of Sports Sciences, 24, 241-251.

Kilanowski, C.K., Conslavi, A.R., \& Epstein, L.H. (1999). Validation of an electronic pedometer for measurements of physical activity in children. Pediatric Exercise Science, 11, 63-68.

Kohl, H.W., Fulton, J.E., \& Caspersen, C.J. (2000). Assessment of physical activity among children and adolescents: A review and synthesis. Preventive Medicine, 31, S54S76.

Le Masurier, G.C., \& Tudor-Locke, C. (2003). Comparison of pedometer and accelerometer accuracy under controlled conditions. Medicine and Science in Sports and Exercise, 35, 867-871.

Le Masurier, G.C., Lee, S.M., \& Tudor-Locke, C. (2004). Motion sensor accuracy under controlled and free-living conditions. Medicine and Science in Sports and Exercise, 36, 905-910.

Longmuir, P.E., \& Bar-Or, O. (2000). Factors influencing the physical activity levels of youths with physical and sensory disabilities. Adapted Physical Activity Quarterly, $17,40-53$.

Louie, L., Eston, R.G., Rowlands, A.V., Tong, K.K., Ingledew, D.K., \& Fu, F.H. (1999). Validity of heart rate, pedometry, and acclerometry for estimating the energy cost of activity in Hong Kong Chinese boys. Pediatric Exercise Science, 11, 229-239.

McArdle, P. (2001). Children's play. Child, Care. Health and Devlopment, 27, 509-514.

Nishikido, N., Kashiwazaki, H., \& Suzuki, T. (1982). Preschool children's daily activities: Direct observation, pedometry, or questionnaire. Journal of Human Ergology, 11, 214-218.

Pellegrini, A. (1990). Elementary school children's playground behavior: Implications for social cognitive development. Children's Environmental Quarterly, 7, 8-16.

Ramirez-Marrero, F., Smith, B.A., Kirby, T.E., Leenders, N., \& Sherman, W.M. (2002). Evlauation of a step-dcounter during treadmill walking in 7-12 year old AfricanAmerican children. Journal of National Black Nurses' Association, 13, 1-5.

Riddoch, C., Andersen, L.B., Wedderkoop, N., Harro, M., Klasson-Heggeb $\emptyset$, L., Sardinha, L.B., et al. (2004). Physical activity levels and patterns of 9-and 15-yr-old European children. Medicine and Science in Sports and Exercise, 36, 86-92.

Rimmer, J.A., \& Rowland, J.L. (2008). Physical activity for youth with disabilities: A critical need in an underserved population. Developmental Neurorehabilitation, 11(2), $141-148$.

Rowlands, A.V. (2001). Field methods of assessing physical activity and energy balance. In R. Eston \& T. Reilly (Eds.), Kinanthropometry and exercise physiology laboratory manual (pp. 151-170). New York: Routledge. 
Rowlands, A.V., Eston, R.G., \& Ingledew, D.K. (1997). Measurement of physical activity in children and adolescents with particular reference to the use of heart rate and pedometry. Sports Medicine (Auckland, N.Z.), 24, 258-272.

Saris, W.H.M. (1986). Habitual activity in children: Methodology and findings in health and disease. Medicine and Science in Sports and Exercise, 18, 253-263.

Schneider, P.L., Crouter, S.E., Lukajic, O., \& Bassett, D.R. (2003). Accuracy and reliability of 10 pedometers for measuring steps over a 400-m walk. Medicine and Science in Sports and Exercise, 35, 1779-1784.

Schneider, P.I., Crouter, S.E., \& Bassett, D.R. (2004). Pedometer measures of free-living physical activity: Comparison of 13 models. Medicine and Science in Sports and Exercise, 36, 331-335.

Scruggs, P.W., Beveridge, S.K., Eisenman, P.A., Watson, D.L., Shultz, B.B., \& Ransdell, L.B. (2003). Quantifying physical activity via pedometry in elementary physical education. Medicine and Science in Sports and Exercise, 35, 1065-1071.

Scruggs, P.W., Beveridge, S.K., Watson, D.L., \& Clocksin, B.D. (2005). Quantifying physical activity in first-through fourth-grade physical education via pedometry. Research Quarterly for Exercise and Sport, 76, 166-175.

Scruggs, P.W. (2007). A comparative analysis of pedometry in measuring physical activity of children. Medicine and Science in Sports and Exercise, 39, 1837-1846.

Sherrill, C., \& O'Conner, J. (1999). Guidelines for improving adapted physical activity research. Adapted Physical Activity Quarterly, 16, 1-8.

Stanish, H.I. (2004). Accuracy of pedometers and walking activity in adults with mental retardation. Adapted Physical Activity Quarterly, 21, 167-179.

Strong W., Malina, R.M., Blimkie, C.J.R., Daniels, S.R., Dishman, R.K., Gutin, B., A.C. Hergenroeder, A.C., Must, A., Nixon, P.A., Pivarnik, J.M. Rowland, T., Trost, S., \& F. Trudeau, F. (2005). Evidence based physical activity for school-age youth. The Journal of Pediatrics, 146, 732-737.

Tudor-Locke, C., Williams, J.E., Reis, J.P., \& Pluto, D. (2002). Utility of pedometers for assessing physical activity. Construct validity. Sports Medicine (Auckland, N.Z.), 32, 795-808.

Vincent, S.D., \& Sidman, C.L. (2003). Determining measurement error in digital pedometers. Measurement in Physical Education and Exercise Science, 7, 19-24. 